\title{
INVESTIGATION OF FOOD POISONING OUTBREAK FROM FACTORY-PROVIDED LUNCH CATERING
}

\author{
Arik Iskandar, Nur Hayati \\ Master of Public Health Program, Faculty of Public Health, \\ Universitas Gadjah Mada, Yogyakarta
}

\begin{abstract}
Background: On January 9, 2021, Tegalrejo Community Health Center reported suspect food poisoning. It is postulated that the food poisoning stem from gastrointestinal illness resulting from the consumption of lunch provided by factory. This study aimed to investigate the presence of an outbreak and to determine the source and mode of transmission.

Subjects and Method: This was a case-control study conducted with 1:2 case-control ratio. A total sample of 167 was selected. Cases were those who consumed lunch from catering on January 8, 2021 and experienced symptoms such as diarrhea, nausea, and stomach ache on January 8-9, 2021. Likewise, controls were those who consumed lunch from catering on January 8, 2021 but had no symptoms. Data was collected through interviews using questionnaires and google forms. Food handlers were interviewed for environmental investigation. Attack rate (AR) was used to describe the risk of poisoning. Odds ratio was used to estimate food with the highest risk for poisoning. Food samples were sent to a laboratory in Yogyakarta.

Results: 53 people were found ill $(\mathrm{AR}=31.7 \% ; \mathrm{n}=167)$. Out of the 53 people who were ill, $98.1 \%$ experienced diarrhea and $28.3 \%$ had stomach ache. The average incubation time was 12 hours, with a minimum of 4 hours and maximum of 19 hours 35 minutes. Vegetable fritter was suspected to be the source of poisoning $(\mathrm{OR}=2.17 ; 95 \% \mathrm{CI}=1.00$ to 4.73; $\mathrm{p}=0.049)$. Bacillus cereus was found in the vegetable fritter. Lack of hygiene in the kitchen, improper food handling and storage, might have facilitated contamination and spore growth. Investigation results were reported to the public health official to prevent polemic within the community.

Conclusion: The food poisoning outbreak in a factory was caused by Bacillus cereus in the vegetable fritter. The caterer needs to implement standard health and safety food handling and procedure, and the district health office should provide training on these to ensure safe food for the community.
\end{abstract}

Keywords: food poisoning, bacillus cereus, vegetable fritter.

\section{Correspondence:}

Arik Iskandar. Master of Public Health Program, Faculty of Public Health, Universitas Gadjah Mada, Yogyakarta. Jl. Farmako, Senolowo, Sekip Utara, Depok, Sleman, Yogyakarta 55281Email: arikiskandar24@gmail.com. Mobile: 082325044859.

The $8^{\text {th }}$ International Conference on Public Health Solo, Indonesia, November 17-18, 2021 | 61 https://doi.org/10.26911/AB.Epidemiology.ICPH.08.2021.41 